\title{
Development of an indoor testing rig for façade integrated solar thermal collectors
}

\author{
Macedon Moldovan ${ }^{1, *}$, and Ion Vișa ${ }^{1}$ \\ ${ }^{1}$ Renewable Energy Systems and Recycling Research Centre, R\&D Institute of the Transilvania University of Brasov, Romania
}

\begin{abstract}
New solar thermal collectors with triangular and trapezoidal shapes and different colours (red, blue, green etc.) were developed in the Renewable Energy Systems and Recycling Research Centre, R\&D Institute of the Transilvania University of Brasov, Romania to increase their architectural acceptance when integrated in buildings façades. An indoor testing rig was developed to assess: a) the performance of the new solar thermal collectors vertically installed on the façade, b) the influence of the façade integrated solar thermal collectors on the building envelope and thus on the indoor thermal comfort, $c$ ) the influence of the building envelope on the solar thermal collectors efficiency. The design process of the indoor testing rig is presented in the paper along with numerical simulations and experimental results.
\end{abstract}

\section{Introduction}

Nearly Zero Energy Buildings (nZEB) [1] and nearly Zero Energy Communities (nZEC) are core topics in this climate changes dominated period [2]. By 31 December 2018, all new public buildings should comply with nZEB standard, meaning high-energy efficient buildings and large shares of renewable energy covering their decreased energy demand [1]. This will be mandatory for all new buildings starting with 31 of December 2020. The new EU Directive 2018/844 stipulates that Each Member State shall establish a long-term renovation strategy of both public and private national stock of residential and nonresidential buildings, targeting the cost-effective transformation of existing buildings into nearly zeroenergy buildings and thus decarbonised the buildings stock by 2050 [3]. The ambitious long-term goal is to reduce by 2050 the greenhouse gas emissions in the Union by $80-95 \%$ compared to 1990 .

A larger renewable energy share in the energy demand can be obtained by increasing the capacity of the building integrated solar thermal systems [4] or by implementing renewable based energy mixes [5]. Their main advantages consist on the easy access to the solar energy and the maturity of the technology but there are also drawbacks such as the high variability of the solar radiation and the mismatch between the energy production and energy consumption periods (except solar cooling systems). Also, there were reported issues related to the competition between different facilities installed on the available surfaces of the buildings' envelope and other barriers such shadowing and architectural acceptance [6]. Thus, suitably oriented façades should be considered to integrate solar thermal collectors (STC), obtaining thus solar thermal facades with increased feasibility [7].
Novel trapezoidal flat plate STC were designed developed and experimentally optimized [8] to be integrated in the buildings facades [9]. Further, novel arrangements of these trapezoidal STC were proposed [10] to increase the architectural acceptance and thermal energy output of solar thermal facades. The trapezoidal STC presented also good efficiency and reliability when implemented in an outdoor testing rig for STC [11].

Other novel flat plate STC with triangular shape were developed to increase the design flexibility of building integrated solar thermal systems (BISTS) and the concept was experimentally validated in standard conditions on an indoor testing rig.

Besides the thermal output of the façade integrated STC, their influence on the building envelope is of interest, the building façade being transformed from a passive to an active element. In addition, the building envelope increases its thermal insulation and thus positively influences the STC efficiency. The design process of an indoor testing rig for façade integrated STC is presented in the paper along with numerical simulations and experimental results.

\section{Methodology}

To evaluate the mutual influence between the STC and the building façade, an indoor testing rig for façade integrated STC is used to assess:

- the performance of the new STC vertically installed on the façade;

- the influence of the façade integrated STC on the building envelope and thus on the indoor thermal comfort; - the influence of the building envelope on the STC efficiency.

\footnotetext{
* Corresponding author: macedon.moldovan@unitbv.ro
} 
The STC performance is expressed through its efficiency defined as the ratio between the STC thermal power output $\left(\mathrm{P}_{\mathrm{t}}\right)$ and the intensity of received solar irradiance $(\mathrm{G})$ received on the absorber surface $\left(\mathrm{S}_{\mathrm{a}}\right)$ of the STC using:

$$
\eta=\frac{P_{t}}{S_{a} \cdot G}
$$

The STC thermal power output $\left(\mathrm{P}_{\mathrm{t}}\right)$ is calculated each minute using:

$$
P_{t}=\dot{m} c\left(t_{o}-t_{i}\right)
$$

where $\dot{\mathrm{m}}[\mathrm{kg} / \mathrm{s}]$ is the measured mass flow rate of the fluid through the STC, c $\left[\mathrm{J} /\left(\mathrm{kg} \cdot{ }^{\circ} \mathrm{C}\right)\right]$ is the specific heat at constant pressure of the thermal fluid and $\mathrm{t}_{\mathrm{i}, \mathrm{o}}\left[{ }^{\circ} \mathrm{C}\right]$ are the measured STC inlet/outlet temperatures.

The influence of the façade integrated STC on the building envelope and thus on the indoor thermal comfort can be assessed measuring the temperatures inside the wall structure in the areas with and without integrated STC. The influence of the building envelope on the STC efficiency can be evaluated comparing the efficiency of a STC integrated into the building façade against the efficiency of a STC attached to the building façade.

\section{Indoor testing rig design and development}

A new indoor testing rig for façade integrated solar thermal collectors was added to the research infrastructure of the Renewable Energy Systems and Recycling Research Centre (RESREC) developed in the new R\&D Institute of the Transilvania University of Brasov, Romania. This indoor testing rig for façade integrated solar thermal collectors was developed throughout research project (SolTriCol) financed by the Romanian National Authority for Scientific Research and Innovation, and it is used with an vertical solar simulator previously developed in RESREC Research Centre.

\subsection{Indoor testing rig design}

The indoor testing rig for façade integrated solar thermal collectors was firstly 3D designed in SolidWorks. It consists of a wheels fitted aluminium structure supporting the solar thermal collectors on one side (Figure 1a) and the components of the solar circuit (storage tanks, pumping groups, expansion vessels, controllers etc.) on the other side (Figure 1b). Between the collector side and the components side, there is an empty space with an adjustable width where different layers can be placed to simulate various wall types. The indoor testing rig has an active area of $1500 \times 1500 \mathrm{~mm}$ being designed to test small size solar thermal collectors serially or parallely connected, but it can be also used for commercial solar thermal collectors with a surface up to $2.5 \mathrm{~m}^{2}$. Two identical pumping groups connected to two storage tanks of 80 litres each allow parallel testing of two solar thermal collectors (or groups of collectors) in the same time, shortening thus the testing period.

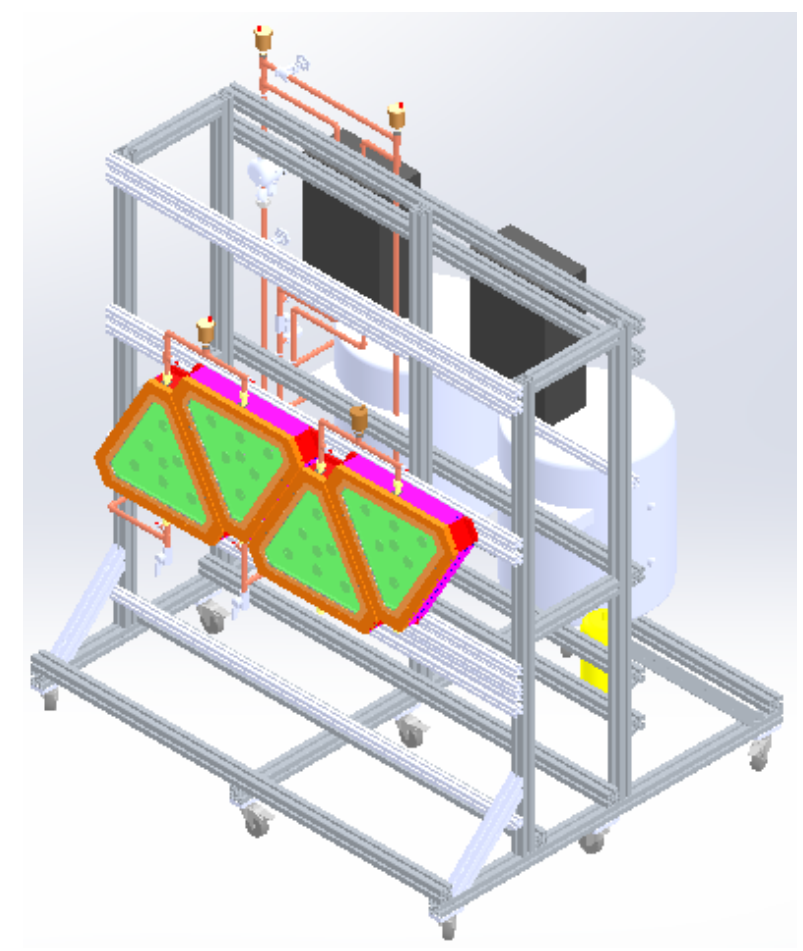

a)

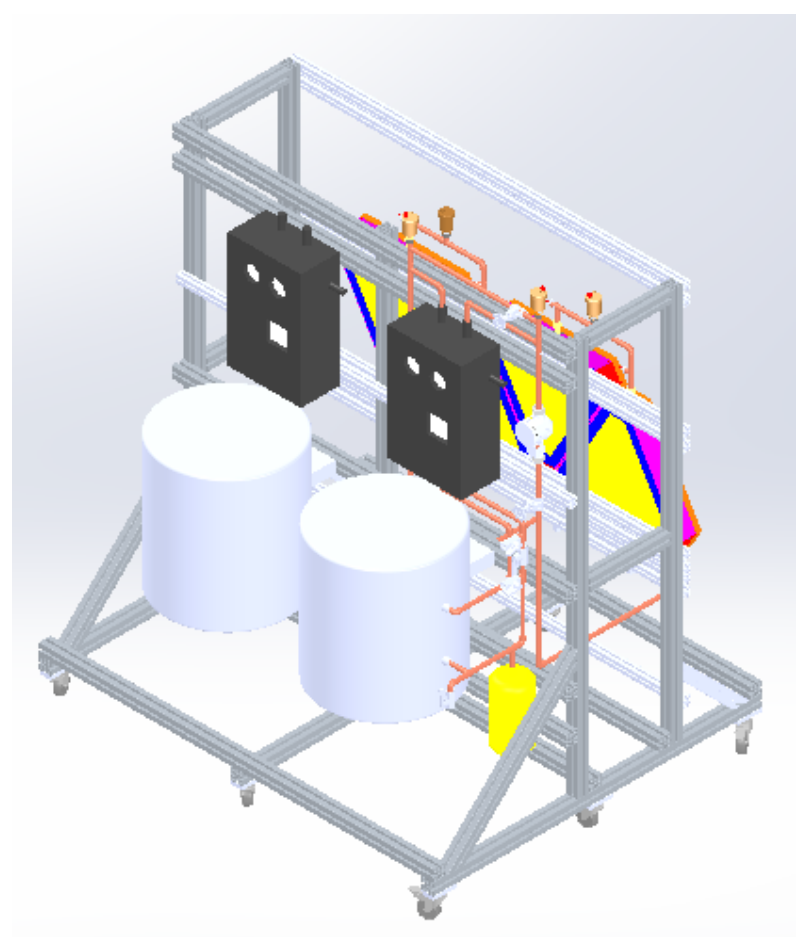

b)

Fig. 1. Virtual 3D model of the indoor testing rig for façade integrated solar thermal collectors: isometric view of the side with installed solar thermal collectors (a) and of the side with solar circuit components (b). 
Up to four triangular solar thermal collectors can be serially connected in a row (Figure 2) and three such rows can be further serially connected to evaluate the influence of the temperature rise on each solar thermal collector efficiency and thus to establish the maximum number of serial connected solar thermal collectors.

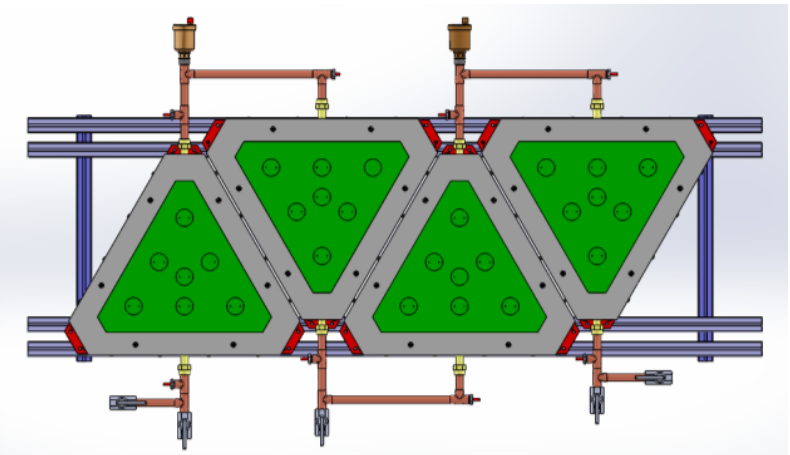

Fig. 2. Triangular solar thermal collectors serially connected.

In the case of the solar thermal collectors with various absorber colours, up to four such collectors can be parallely connected to test their efficiency in the same time and in the same conditions (Figure 3).

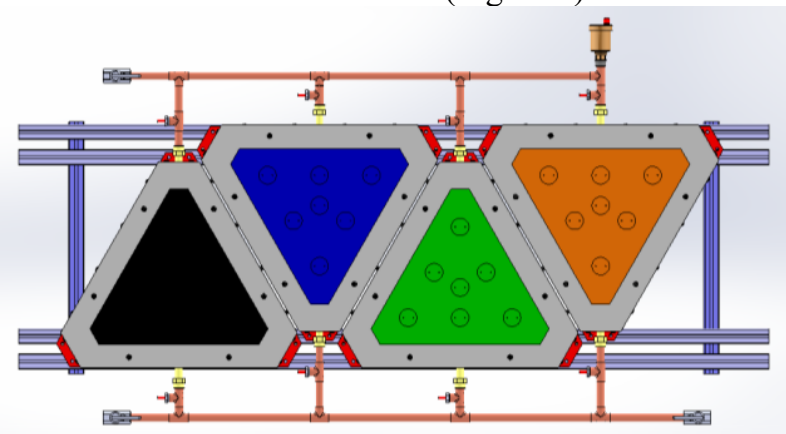

Fig. 3. Triangular solar thermal collectors parallely connected.

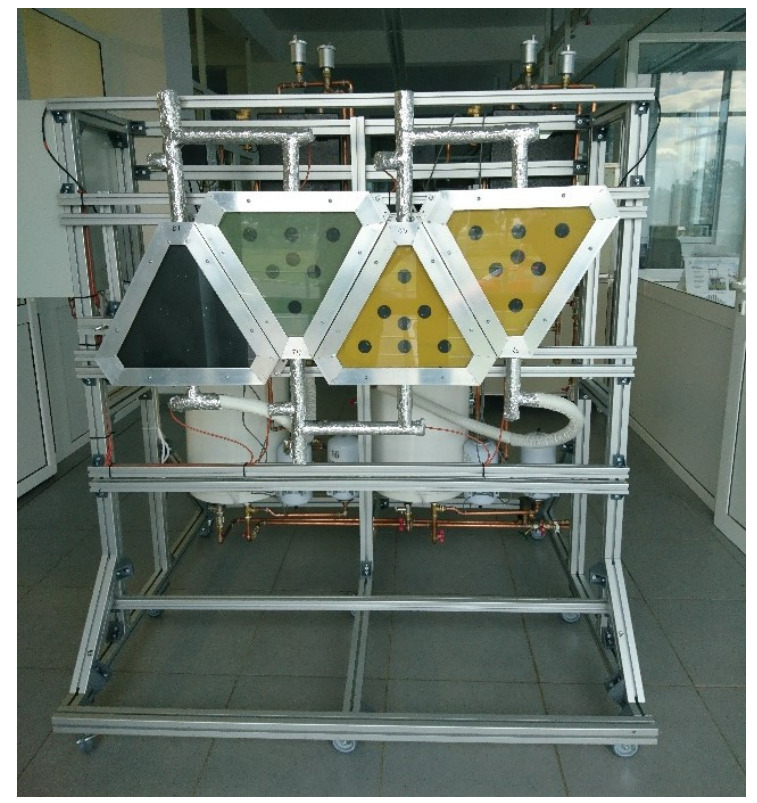

a)

\subsection{Indoor testing rig development}

Aluminium alloy profiles were used to realize a structure to sustain the solar thermal collectors on one side (Figure 4a) and the solar circuit components on the other side (Figure 4b). The structure was designed to be adjustable in order to accommodate different types of solar thermal collectors, storage tanks, pumping groups, expansion vessels etc. Four flat plate solar thermal collectors of triangular shape and various colours (black, green and orange) were mounted on the structure. The solar thermal collectors were serially interconnected using insulated copper pipes; stainless steel flexible pipes are used to connect the group of four solar collectors to a Buderus Logasol KS0120 solar station (equipped with a Grundfos UPS 25-80 variable flow pump) further connected to a storage tank with a capacity of 80 litres. Each storage tank is equipped with a built-in $3 \mathrm{~kW}$ electrical heater allowing thus the inlet temperature adjustment through a controller. Temperature sensors Pt1000 with an accuracy of $\pm 0.1{ }^{\circ} \mathrm{C}$ are installed on each inlet and outlet of the solar thermal collector and on the storage tank. A similar temperature sensor is used to measure the ambient temperature. A magnetic-inductive flow meter IFM - SM4000 with an accuracy of $\pm 0.5 \%$ is used to measure the flow in the hydraulic circuit of the solar thermal collectors. The mass flow can be electronically adjusted through each circuit according to the absorber surface of the tested solar thermal collector/s. The solar irradiance is measured in the solar thermal collector's plane with an LSI BSR 153 pyranometer, with a spectral range within 300 and 3000 $\mathrm{nm}$ and an achievable uncertainty $95 \%$ confidential level lower than $5 \%$. A monitoring system is used for shortterm data logging from which data is transferred to a computer database for storage, processing and analysis.

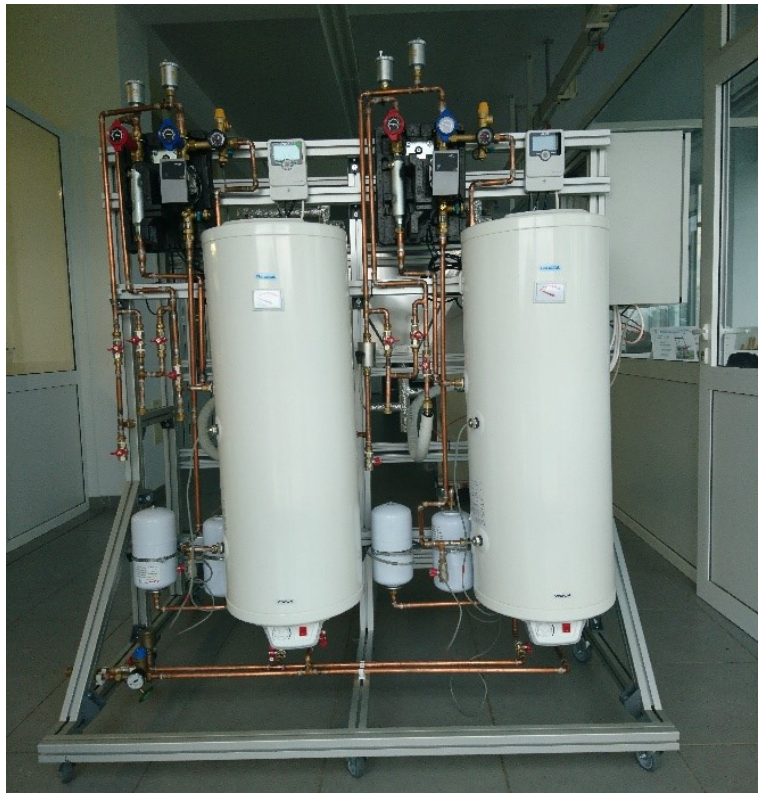

b)

Figure 4: The indoor testing rig for façade integrated solar thermal collectors: view of the side with installed solar thermal collectors (a) and of the side with solar circuit components (b). 
Table 1. Fluent model constants.

\section{Results and discussions}

\subsection{Flow simulations}

In the first stage of the design process, flow simulations were performed in Ansys-Fluent R15.0, which uses the Finite Volume Method (FVM) to assess the influence of the STC interconnections on the flow distribution. Therefore, the flow of the thermal fluid was further modelled through four serially (Figure 5a) and parallely (Figure 5b) connected solar thermal collectors. Each STC and the pipes interconnecting the STCs were 3D modelled using Geometry module in Ansys Workbench and further connected to Fluid Flow (Fluent) module where meshes with 18195 nodes and 17005 elements (for STC serially connected) and 19701 nodes and 18331 elements (for STC parallely connected) were generated using advanced sizing function on curvature with fine relevance center, high smoothing and fine span angle center. The orthogonal quality of the meshes resulted 0.691 and 0.654 for serially connected STC, values corresponding to good mesh quality. Water-liquid was considered as fluid and aluminium/cooper as solid materials for STCs and pipes respectively. The boundary conditions of the model were defined as follows: the inlet was set as a velocity-inlet zone with a normal to boundary direction, an absolute magnitude of $33 \mathrm{~mm} / \mathrm{s}$ for each solar thermal collector (corresponding to a specific flow rate of $0.02 \mathrm{~kg} / \mathrm{m}^{2} / \mathrm{s}$, an absorber plate area of $0.083 \mathrm{~m}^{2}$ and an inner diameter of the inlet and outlet pipes of $8 \mathrm{~mm}$ ), a turbulent intensity of $5 \%$ and a turbulent viscosity ratio of 10 ; the outlet was set as a pressure-outlet zone with a backflow turbulent intensity of $5 \%$ and a backflow turbulent viscosity ratio of 10; the other surfaces were considered stationary walls with no slip shear condition. Further on, the Fluent solver was set up for pressure-based and absolute velocity steady-state calculations, with gravitational acceleration considered on $-\mathrm{Y}$ axis direction, using the viscous realizable k- $\varepsilon$ (2 equation) model, standard wall functions for near-wall treatment. Default reference values were used and $300 \mathrm{~K}$ as medium temperature, the model constants are presented in Table 1.

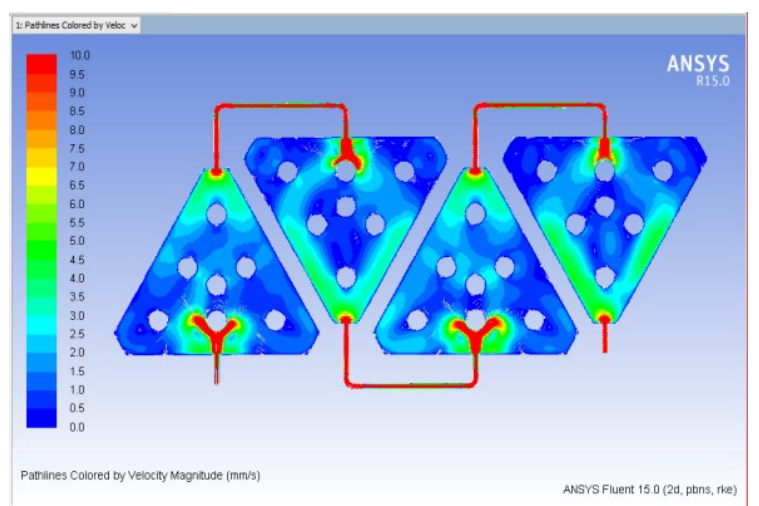

a)

\begin{tabular}{|c|c|}
\hline Model constant & Value \\
\hline C2-Epsilon & 1.9 \\
\hline TKE Prandtl Number & 1 \\
\hline TDR Prandtl Number & 1.2 \\
\hline Energy Prandtl Number & 0.85 \\
\hline Wall Prandtl Number & 0.85 \\
\hline
\end{tabular}
converged after $154^{\text {th }}$ iteration and $148 \mathrm{~s}$. zones.

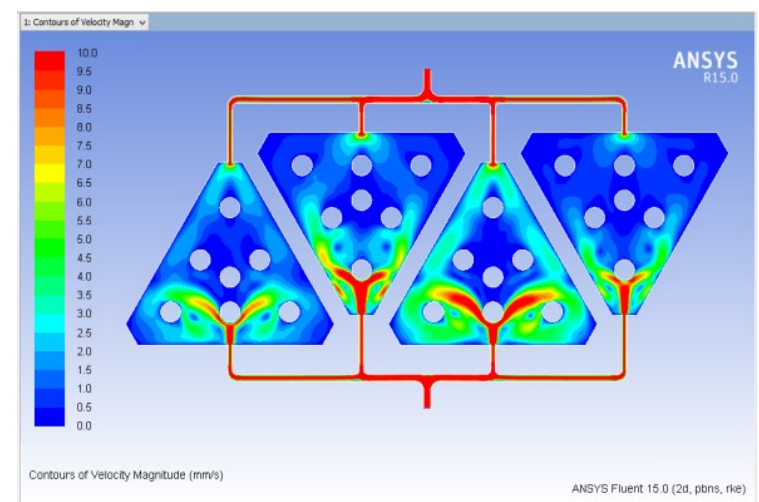

b)

A SIMPLE scheme was chosen as the pressurevelocity coupling method along with a spatial discretization characterized by least squares cell based gradient, second order pressure, second order upwind momentum, first order upwind turbulent kinetic energy, first order upwind turbulent dissipation rate, and second order upwind energy. Standard initialization was used in solution computing, considering the reference frame relative to cell zone. Default Under-Relaxation factors were used in solution controls during the simulation to promote convergence. Two control monitors of the iterative process were defined to check convergence: a monitor for the residuals of the iterative process for the equations solved and the monitor of the velocity. When the residual decreases at a value of $10^{-3}$, the simulation process is considered to be convergent, while the velocity monitor exhibits a constant trend. The time step was set to $1 \mathrm{~s}$ and the number of iteration to 5000 . The solution

To evaluate the existence of stagnation areas inside the solar thermal collectors, the ranges of the displayed flow rate was successively limited at $1 \mathrm{~mm} / \mathrm{s}$ and $0.1 \mathrm{~mm} / \mathrm{s}$ and plotted in Figures 6a-6d respectively, where all the regions with flow rates exceeding the threshold are red. Analysing the flow rate distribution presented in Figures $6 a-6 d$ it can be concluded that the serial or parallel connection of the four STCs does not lead to stagnation

Fig. 5. Flow simulations through the triangular solar thermal collectors serially (a) and parallely (b) connected, with the velocity plotting range between 0 and $10 \mathrm{~mm} / \mathrm{s}$. 


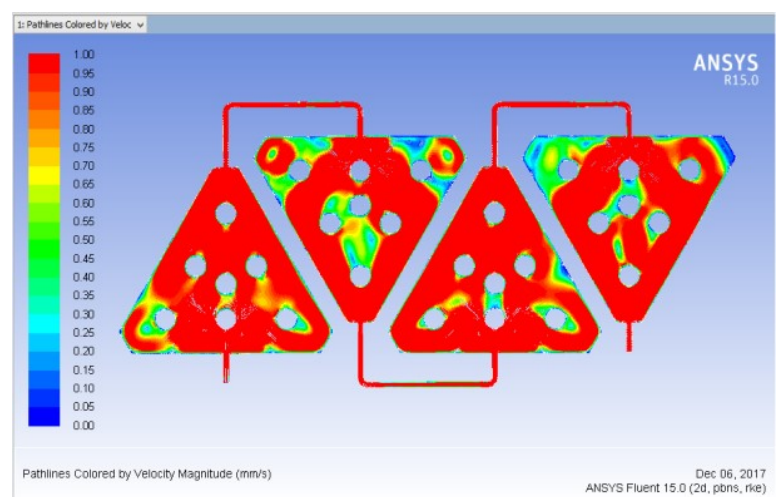

a)

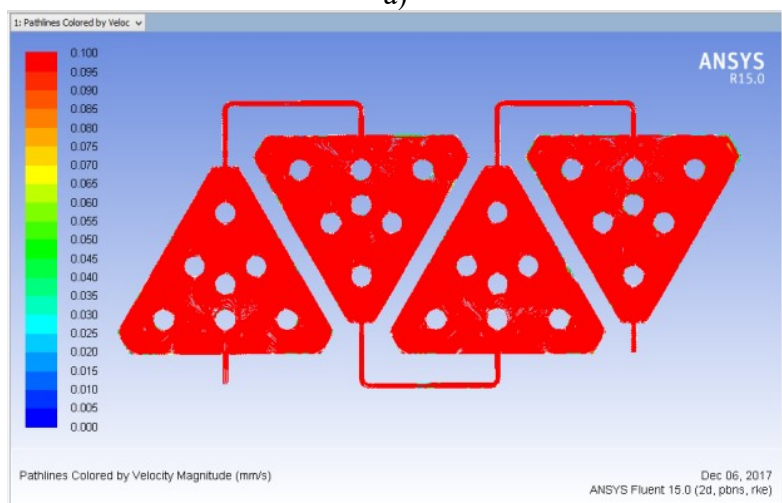

c)

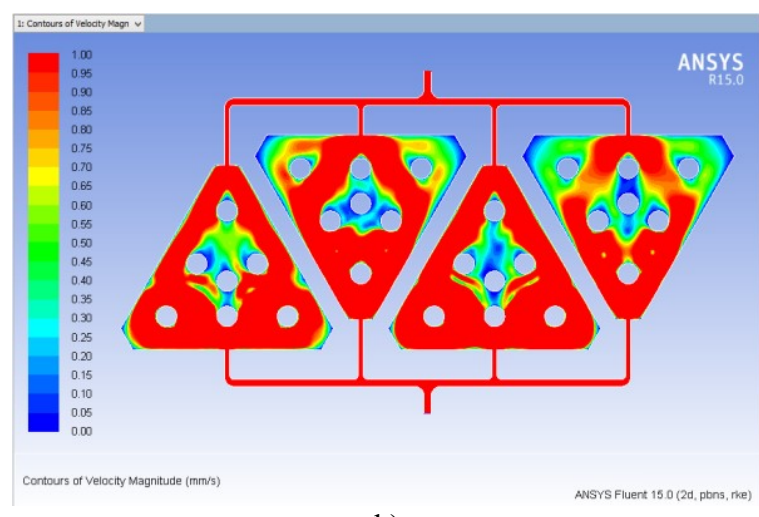

b)

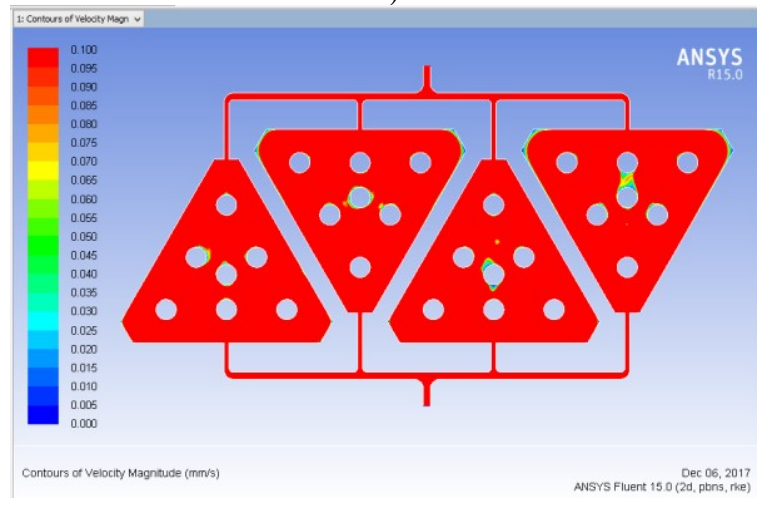

d)

Fig. 6. Flow simulations through the triangular solar thermal collectors serially (a and c) and parallely (b and d) connected, with the velocity plotting range between 0 and $1 \mathrm{~mm} / \mathrm{s}$ ( $\mathrm{a}$ and $\mathrm{b}$ ) and between 0 and $0.1 \mathrm{~mm} / \mathrm{s}$ (c and d).

\subsection{Indoor testing}

Four triangular solar thermal collectors with various colours (one black, one green and two orange) were installed on the indoor testing rig, serially interconnected in the hydraulic circuit, which was filled with water. The group of four STCs were exposed to $1000 \mathrm{~W} / \mathrm{m}^{2}$ solar radiation obtained through a vertical solar simulator (Figure 7) to evaluate its efficiency according to ISO 9806:2017 solar thermal collectors testing standard [12].

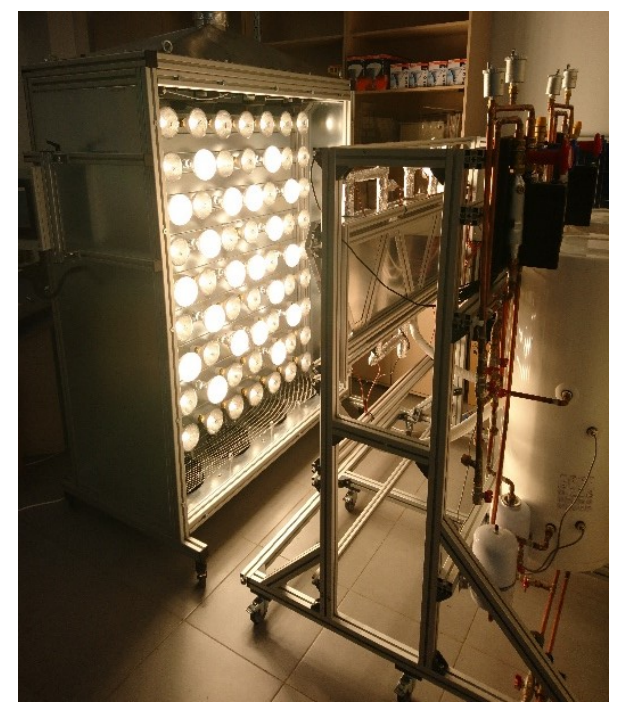

Fig. 7. The indoor testing rig for façade integrated solar thermal collectors exposed to the vertical solar simulator.
Based on the temperature measured at the inlet of the first STC and at the outlet temperature of the last STC, the overall efficiency of the group of four serially connected STCs was calculated and plotted in Figure 8 against the temperature difference between the average STCs temperature and the ambient temperature $\left(T_{m}-T_{a}\right)$ divided by the total solar radiation intensity $(\mathrm{G})$ showing a nominal efficiency of $46.79 \%$. The results can be qualified as good ones, considering that only one solar thermal collector has a black coated absorber, the second is green and the last two ones are orange.

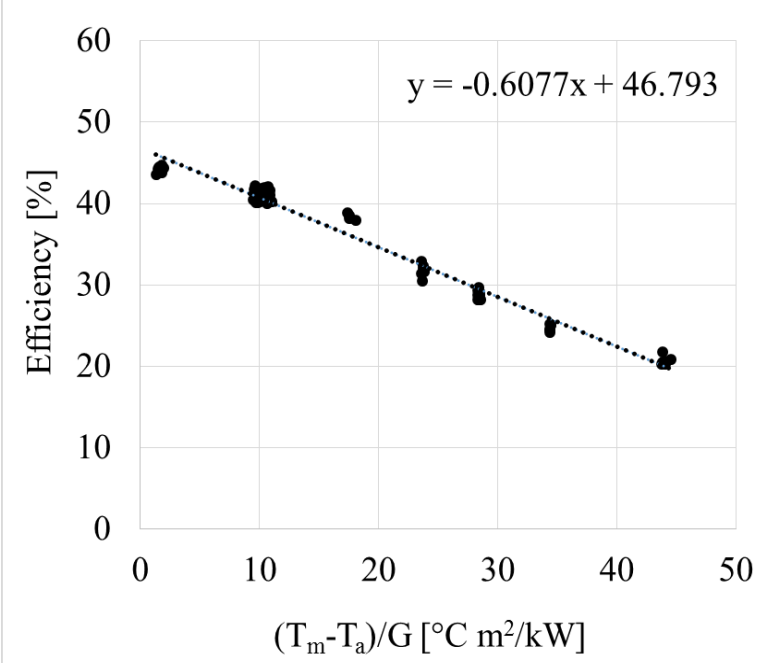

Fig. 8. Efficiency results plotted for the group of four serially connected solar thermal collectors. 


\section{Conclusions}

The design and development process of an indoor testing rig for façade integrated solar thermal collectors implemented in the Renewable Energy Systems and Recycling Research Centre (RESREC) of the R\&D Institute of the Transilvania University of Brasov, Romania are presented in the paper. This indoor testing rig can be used to evaluate the performance of the new solar thermal collectors vertically installed on the façade, the influence of the façade integrated solar thermal collectors on the building envelope and thus on the indoor thermal comfort, and the influence of the building envelope on the solar thermal collectors efficiency.

Numerical simulations performed in Ansys showed that the flow is nor disturbed or presenting stagnation zones through four serially or parallely connected façade integrated solar thermal collectors.

An experimental nominal efficiency of $46.79 \%$ was obtained for the group of four serially connected solar thermal collectors, this value being considered as good one tacking into account the colours of the solar thermal collectors' absorbers (black, green and orange).

Further research studies will be developed in the field of the mutual influence between the façade integrated solar thermal collectors and the building façade.

This work was supported by a grant of the Romanian National Authority for Scientific Research and Innovation CNCS/CCCDI-UEFISCDI, project no. PN-III-P-2.2.1-PED2016-0338, within PNCDI III.

\section{References}

1. European Union, Directive 2010/31/EU on the energy performance of buildings. Official Journal of the European Union 18.6.2010 L153, 13-35 (2010).

2. I. Visa, A. Duta, Nearly Zero Energy Communities, Springer (2017)

3. European Union, Directive (EU) 2018/844 of the European Parliament and of the Council of 30 May 2018 amending Directive 2010/31/EU on the energy performance of buildings and Directive 2012/27/EU on energy efficiency. Official Journal of the European Union L156/75, 75-91, (2018)

4. C. Maurer, C. Cappel, T. Kuhn, Progress in buildingintegrated solar thermal systems, Sol Energy, 154, 158-186 (2017)

5. M. Moldovan, I. Visa, M. Neagoe, B. Burduhos, Solar heating\&cooling energy mixes to transform low energy buildings in nearly zero energy buildings, Energy Procedia, 48, 924-937 (2014)

6. M. C. Munari Probst, Architectural Integration and Design of Solar Thermal Systems, Lausanne, Suisse: EPFL Press (2011)

7. R. O'Hegarty, O. Kinnane, S.J. McCormack, Review and analysis of solar thermal facades, Sol Energy, 135, 408-422 (2016)

8. I. Visa, A. Duta, M. Comsit, M. Moldovan, D. Ciobanu, R. Saulescu, B. Burduhos, Design and experimental optimisation of a novel flat plate solar thermal collector with trapezoidal shape for facades integration, Appl. Therm. Eng., 90, 432-443 (2015)

9. I. Visa, M. Moldovan, M. Comsit, M. Neagoe, A. Duta, Facades integrated solar-thermal collectors challenges and solutions, Energy Procedia, 112, 176185 (2017)

10. I. Visa, M. Comsit, A. Duta, M. Neagoe, M. Moldovan, B. Burduhos, A. Constantions. Novel Solar-Thermal Collectors/Array With Increased Architectural Acceptance For Building Integration, COST Action TU1205 BISTS - Design and Applications Handbook, 373-390 (2017)

11. I. Visa, A. Duta, M. Moldovan, Outdoor performance of a trapeze solar thermal collector for facades integration, Renewable Energy. doi: https://doi.org/10.1016/j.renene.2018.01.101 (2018)

12. International Organization for Standardization, Solar energy - Solar thermal collectors - Test methods, ISO 9806:2017, (2017) 